\title{
High genetic variability and polychromatism in Pachycoris torridus (Heteroptera: Scutelleridae)
}

T.S. Souza-Firmino ${ }^{1}$, K.C.C. Alevi' ${ }^{2}$, L.L.V. Pereira' ${ }^{1}$, E.R.S. Souza', F.C.S. Júnior ${ }^{1}$, C.A. Banho', G.O. Carmo ${ }^{1}$ and M.M. Itoyama ${ }^{1}$

${ }^{1}$ Laboratório de Citogenética e Molecular de Insetos, Departamento de Biologia, Instituto de Biociências, Letras e Ciências Exatas,

Universidade Estadual Paulista "Júlio de Mesquita Filho",

São José do Rio Preto, SP, Brasil

${ }^{2}$ Laboratório de Biologia Celular, Departamento de Biologia,

Instituto de Biociências, Letras e Ciências Exatas,

Universidade Estadual Paulista "Júlio de Mesquita Filho",

São José do Rio Preto, SP, Brasil

Corresponding author: K.C.C. Alevi

E-mail: kaiochaboli@hotmail.com

Genet. Mol. Res. 14 (4): 14300-14307 (2015)

Received April 25, 2015

Accepted August 19, 2015

Published November 13, 2015

DOI http://dx.doi.org/10.4238/2015.November.13.14

ABSTRACT. The stink bug Pachycoris torridus is listed among the most polyphagous insects in the world and it is a major pest of diverse crops, in particular the physic nut Jatropha curcas, which is used as a raw material for biodiesel production. A peculiar characteristic of this species is its high phenotypic variability, a characteristic that makes identification difficult: $P$. torridus has been described as a new species eight times. Thus, to aid in identification, genetic characterization of this insect was performed. We verified that, due to the high genetic variability of $P$. torridus, several genetic patterns exist that result in the same phenotype.

Key words: Genetic variability; Stink bug; Molecular analysis 


\section{INTRODUCTION}

The Scutelleridae family includes heteropterans of the most varied colors (red, yellow, and orange, among others), and many of these are frequently iridescent. Within Scutelleridae, species with polychromatism are a common occurrence (Sanchez-Soto et al., 2004), as is observed for species within the genus Pachycoris. This polychromatism has created confusion for the identification of species, such as Pachycoris klugii, Pachycoris stallii, and P. torridus (Peredo, 2002).

The stink bug $P$. torridus is the only species in the family Scutelleridae with agricultural importance in Brazil, and it is popularly known as the "stink bug of the physic nut" due to its attacks on crops of the physic nut Jatropha curcas, which is used as raw material for biodiesel production (Silva el al., 1968). However, this is not the only plant where these insects are found. There are reports of $P$. torridus on Anacardiaceae (Anacardium occidentale, Mangifera indica, Schinus terebinthifolius), Boraginaceae (Cordia sp.), Euphorbiaceae (Aleurites fordii, Cnidoscolus pubescens, Jatropha curcas, Jatropha sp., Manihot esculenta, Sapium haematospermum), Malpighiaceae (Malpighia glabra), Myrtaceae (Eucalyptus sp., Psidium araca, Psidium guajava), Poaceae (Oryza sativa), Rubiaceae (Coffea sp.), and Rutaceae (Citrus sinensis) (Marques et al., 2012). Thus, this species is considered one of the most polyphagous insects in the world. Stink bugs are widely distributed in America, being found from the United States to Argentina (Froeschner, 1988).

$P$. torridus possess several variations in the patterns of spots and colors on its body (Monte, 1937), a characteristic that has resulted in this species being described as new species eight times (Lima, 1940), with names such as Tetyra schousboei, Pentatoma fabricii, Scutellera decorata, P. klugii, P. linaei, P. aquila, P. stallii, and Poecilocoris aeneiventris (Maes, 1994). The most common form of $P$. torridus is the one that presents 22 spots, eight on the pronotum and 14 on the scutellum, where they are neatly arranged on the scutellum in four rows of $5,4,3$, and 2 spots, starting from the base to the apex, respectively. The color of the spots is diverse, varying from red to yellow (Monte, 1937).

The variety of colors and patterns on $P$. torridus is governed by a complex set of enzymes, pathways, control elements, and genetics. Some studies have investigated the developmental genetics of cuticular pigmentation in organisms, such as Drosophila melanogaster, providing valuable information about the fundamentals of this important source of polymorphism in all classes of insects (Sugumaran, 1998, 2002, 2009; Wittkopp and Beldade, 2009).

The identification of haplotypes from the simultaneous use of multiple markers has contributed successfully to the determination of the genetic variability of insects (Dotson and Beard, 2001). Therefore, using the cytochrome c oxidase I (COI), 28S rRNA (28S), and 16S rRNA (16S) markers together, we characterized the genetic variability of $P$. torridus, expanding our knowledge of this species, which is considered a pest of great economic value in Brazil.

\section{MATERIAL AND METHODS}

Specimens of $P$. torridus were collected in the cities of Americo de Campos-SP $\left(20^{\circ} 17^{\prime} 43.1^{\prime \prime}\right.$ S, 49 44'12.2" W) and Sao Jose do Rio Preto-SP (2046'48.2” S, 49 $21^{\circ}$ '18.3" W) and transported to the Laboratory of Cytogenetics and Molecular of Insects, at the Universidade Estadual Paulista 
"Julio de Mesquita Filho", Campus of Sao Jose do Rio Preto, Sao Paulo. Identification of the insects was based on the work of Monte (1937) and Lima (1940).

Using tweezers, the muscle was removed from the thorax of specimens fixed in absolute ethanol and DNA was extracted. DNA was extracted from 40 specimens, 20 from each population, including 10 with yellow spots, 15 with orange spots, and 15 with red spots (Figure 1).
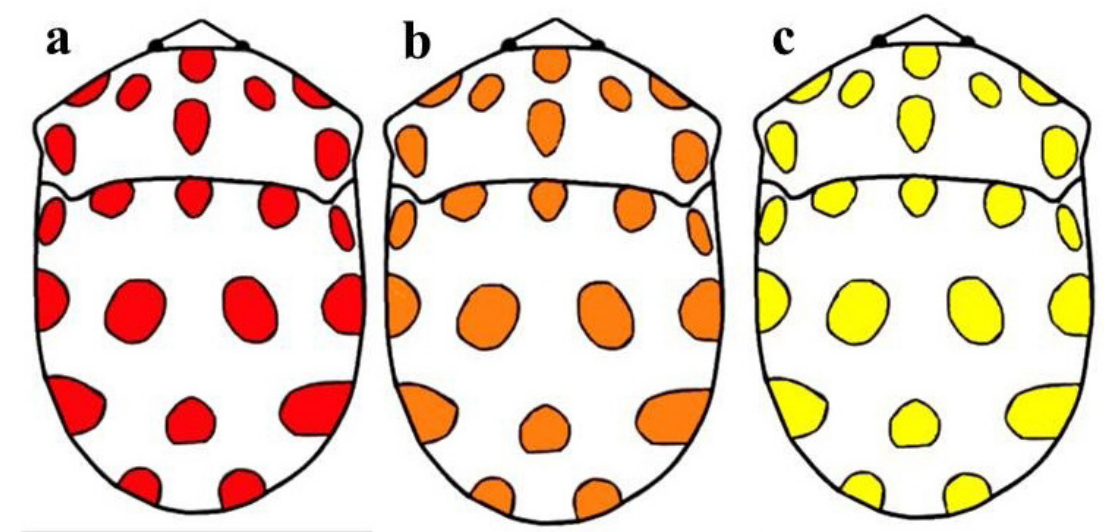

Figure 1. Representative color patterns of specimens of Pachycoris torridus collected from two populations in Brazil: a) red; b) orange; c) yellow.

DNA extraction and sequencing was undertaken following the methodology described in the second protocol by Bargues and Mas-Coma (1997), using the COI, 28S, and 16S markers together concatenated (Table 1).

Table 1. Primer pairs used to amplify fragments of the COI, $28 \mathrm{~S}$, and $16 \mathrm{~S}$ genes in Pachycoris torridus. Expected fragment size and source reference are detailed.

\begin{tabular}{lllcl}
\hline Primes & Foward & Reverse & Size & Reference \\
\hline COI & TTTCAACAAATCATAAAGATATTGG & TAAACTTCAGGGTGACCAAAAATCA & 700pb & Folmer et al. (1994) \\
$28 S$ & CCCGTCTTGAAACACGGACCAA & CCACAGCGCCAGTTCTGCTTAC & $600 \mathrm{pb}$ & Muraji and Tachikama (2000) \\
$16 \mathrm{~S}$ & CRCCTGTTTAACAAAAACAT & AAAAAAATTACGCTGTTATCCCTAAAGTAA & 600pb & Lyman et al. (1999) \\
\hline
\end{tabular}

The sequences obtained were aligned and adjusted manually using the program BioEdit v.7.1.3.0. (Hall, 1999). To undertake genetic characterization of $P$. torridus, nucleotide diversity $(\pi)$, number of haplotypes $(\mathrm{h})$, haplotype diversity $(\mathrm{Hd})$, and the average number of nucleotide differences $(k)$ were calculated using the program DnaSP v5.10 (Librato and Rozas, 2009). MEGA 6.06 (Tamura et al., 2013) was employed to infer genetic relationships among the specimens using the method of maximum likelihood with the model of nucleotide substitution Kimura 2 parameters (Kimura, 1980). The network of connections among haplotypes was obtained to facilitate visualization of the distribution of chromatic patterns among the haplotypes using the program Network v4.6.1.2. (Bandelt et al., 1999).

The sequences generated in this study are available in GenBank and Accession numbers are presented in Table 2. 
Table 2. GenBank accession No. of the sequences utilized in genetic characterization of Pachycoris torridus. Specimens Pt101 to Pt1 20 belong to the Sao Jose do Rio Preto population and specimens Pt2_21 to Pt2_40 belong to the Americo de Campos-SP.

\begin{tabular}{|c|c|c|c|c|c|c|}
\hline Specimen & Primer & No. of access & Primer & No. of access & Primer & No. of access \\
\hline Pt1_01 & $\mathrm{COI}$ & KM257865 & $28 S$ & KM821050 & $16 S$ & KM676295 \\
\hline Pt1_02 & $\mathrm{COI}$ & KM257866 & $28 S$ & KM821051 & $16 S$ & KM676296 \\
\hline Pt1_03 & $\mathrm{COI}$ & KM257867 & $28 S$ & KM821052 & $16 S$ & KM676297 \\
\hline Pt1_04 & $\mathrm{COI}$ & KM257868 & $28 S$ & KM821053 & $16 S$ & KM676298 \\
\hline Pt1_05 & $\mathrm{COI}$ & KM257869 & $28 S$ & KM821054 & $16 S$ & KM676299 \\
\hline Pt1_06 & $\mathrm{COI}$ & KM257870 & $28 S$ & KM821055 & $16 S$ & KM676300 \\
\hline Pt1_07 & $\mathrm{COI}$ & KM257871 & $28 S$ & KM821056 & $16 S$ & KM676301 \\
\hline Pt1_08 & $\mathrm{COI}$ & KM257872 & $28 S$ & KM821057 & $16 S$ & KM676302 \\
\hline Pt1_09 & $\mathrm{COI}$ & KM257873 & $28 S$ & KM821058 & $16 S$ & KM676303 \\
\hline Pt1_10 & $\mathrm{COI}$ & KM257874 & $28 S$ & KM821059 & $16 S$ & KM676304 \\
\hline Pt1_11 & $\mathrm{COI}$ & KM658553 & $28 S$ & KM821060 & $16 S$ & KM676305 \\
\hline Pt1_12 & $\mathrm{COI}$ & KM658554 & $28 S$ & KM821061 & $16 S$ & KM676306 \\
\hline Pt1_13 & $\mathrm{COI}$ & KM658555 & $28 S$ & KM821062 & $16 S$ & KM676307 \\
\hline Pt1_14 & $\mathrm{COI}$ & KM658556 & $28 S$ & KM821063 & $16 S$ & KM676308 \\
\hline Pt1_15 & $\mathrm{COI}$ & KM658557 & $28 S$ & KM821064 & $16 S$ & KM676309 \\
\hline Pt1_16 & $\mathrm{COI}$ & KM658558 & $28 S$ & KM821065 & $16 \mathrm{~S}$ & KM676310 \\
\hline Pt1_17 & $\mathrm{COI}$ & KM658559 & $28 S$ & KM821066 & $16 S$ & KM676311 \\
\hline Pt1_18 & $\mathrm{COI}$ & KM658560 & $28 S$ & KM821067 & $16 S$ & KM676312 \\
\hline Pt1_19 & $\mathrm{COI}$ & KM658561 & $28 S$ & KM821068 & $16 S$ & KM676313 \\
\hline Pt1_20 & $\mathrm{COI}$ & KM658562 & $28 S$ & KM821069 & $16 S$ & KM676314 \\
\hline Pt2_21 & $\mathrm{COI}$ & KM257875 & $28 S$ & KM821070 & $16 S$ & KM676315 \\
\hline Pt2_22 & $\mathrm{COI}$ & KM257876 & $28 S$ & KM821071 & $16 S$ & KM676316 \\
\hline Pt2_23 & $\mathrm{COI}$ & KM257877 & $28 S$ & KM821072 & $16 S$ & KM676317 \\
\hline Pt2_24 & $\mathrm{COI}$ & KM257878 & $28 S$ & KM821073 & $16 S$ & KM676318 \\
\hline Pt2_25 & $\mathrm{COI}$ & KM257879 & $28 S$ & KM821074 & $16 S$ & KM676319 \\
\hline Pt2_26 & $\mathrm{COI}$ & KM257880 & $28 S$ & KM821075 & $16 S$ & KM676320 \\
\hline Pt2_27 & $\mathrm{COI}$ & KM257881 & $28 S$ & KM821076 & $16 S$ & KM676321 \\
\hline Pt2_28 & $\mathrm{COI}$ & KM257882 & $28 S$ & KM821077 & $16 S$ & KM676322 \\
\hline Pt2_29 & $\mathrm{COI}$ & KM257883 & $28 S$ & KM821078 & $16 S$ & KM676323 \\
\hline Pt2_30 & $\mathrm{COI}$ & KM257884 & $28 S$ & KM821079 & $16 S$ & KM676324 \\
\hline Pt2_31 & $\mathrm{COI}$ & KM658563 & $28 S$ & KM821080 & $16 S$ & KM676325 \\
\hline Pt2_32 & $\mathrm{COI}$ & KM658564 & $28 S$ & KM821081 & $16 S$ & KM676326 \\
\hline Pt2_33 & $\mathrm{COI}$ & KM658565 & $28 S$ & KM821082 & $16 S$ & KM676327 \\
\hline Pt2_34 & $\mathrm{COI}$ & KM658566 & $28 S$ & KM821083 & $16 S$ & KM676328 \\
\hline Pt2_35 & $\mathrm{COI}$ & KM658567 & $28 S$ & KM821084 & $16 S$ & KM676329 \\
\hline Pt2_36 & $\mathrm{COI}$ & KM658568 & $28 S$ & KM821085 & $16 S$ & KM676330 \\
\hline Pt2_37 & $\mathrm{COI}$ & KM658569 & $28 S$ & KM821086 & $16 S$ & KM676331 \\
\hline Pt2_38 & $\mathrm{COI}$ & KM658570 & $28 S$ & KM821087 & $16 \mathrm{~S}$ & KM676332 \\
\hline Pt2_39 & $\mathrm{COI}$ & KM658571 & $28 S$ & KM821088 & $16 S$ & KM676333 \\
\hline Pt2_40 & $\mathrm{COI}$ & KM658572 & $28 S$ & KM821089 & $16 S$ & KM676334 \\
\hline
\end{tabular}

\section{RESULTS}

Analyzing the populations of $P$. torridus from Sao Jose do Rio Preto and Americo de Campos, we verified that there were no visible phenotypic differences between the two populations, with both populations presenting the same proportion of insects with yellow, orange, and red spots. After alignment of the sequences generated for the $\mathrm{COI}, 28 \mathrm{~S}$, and $16 \mathrm{~S}$ genes, we observed a total of 1634 sites, of which 1597 were conserved, 37 were varied, 32 were parsimonious, and 5 were single. A total of 40 sequences were analyzed, which presented a nucleotide proportion of $\mathrm{T}=$ 26.8, $A=32.9, C=21.3$, and $G=19.0 \%$, reaffirming the richness of bases $A$ and $T$ described for the mitochondrial genome of insects (Hoy, 2003). The indices of genetic diversity of the species $P$. torridus are presented in Table 3. 
Table 3. Indices of genetic diversity of Pachycoris torridus based on fragments of the COI, 28S, and $16 \mathrm{~S}$ genes.

\begin{tabular}{lc}
\hline Index & Genetic diversity \\
\hline Informative sites $(\mathrm{S})$ & 32 \\
$\mathrm{~N}^{\circ}$ of haplotype $(\mathrm{H})$ & 12 \\
Haplotype diversity $(\mathrm{Hd})$ & 0.872 \\
Nucleotide diversity $(\pi)$ & 0.00737 \\
Average number of nucleotide differences $(\mathrm{k})$ & 12.049 \\
Total number of mutations found $(\eta)$ & 37 \\
\hline
\end{tabular}

Figure 2 details the distribution of the phenotypes analyzed and their evolutionary relationships. We observed separation of the yellow and red phenotypes, with red being more basal in the topology and yellow derived. The orange phenotype appeared to be widely distributed in relation to the other two phenotypes studied.

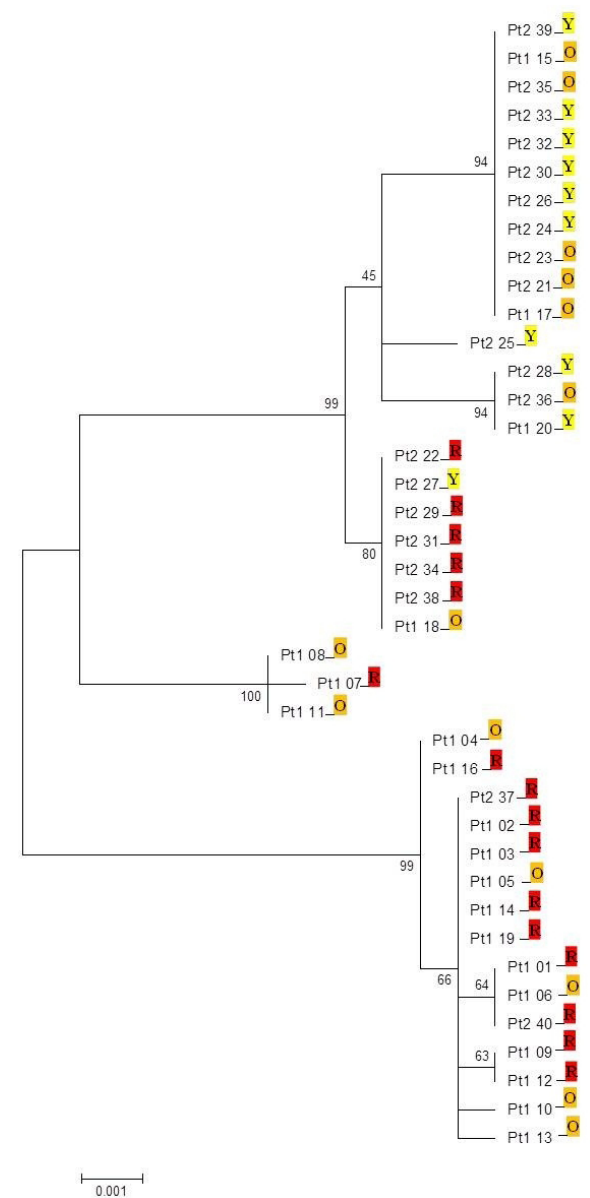

Figure 2. Topology generated for specimens of Pachycoris torridus, obtained from alignment of 40 sequences with 1634 sites each, using the markers $\mathrm{COI}, 28 \mathrm{~S}$, and $16 \mathrm{~S}$ together. Evolutionary history was inferred using the maximum likelihood method with Kimura 2 parameters. The numbers on the tree branches is the percentage ofconfidence with bootstrap of 1000 replicate. Color denotes the actual color of each specimen analyzed. 
Considering the total number of informative sites based on the analysis of minimum evolution using the program Network, it was possible to observe the connections between the haplotypes and phenotypes studied. To facilitate visualization of the phenotypic distribution, each haplotype was represented by the color of the specimens (Figure 3). The distribution of the color patterns was similar to that obtained in the topology analysis, confirming the relationship between phenotypes.

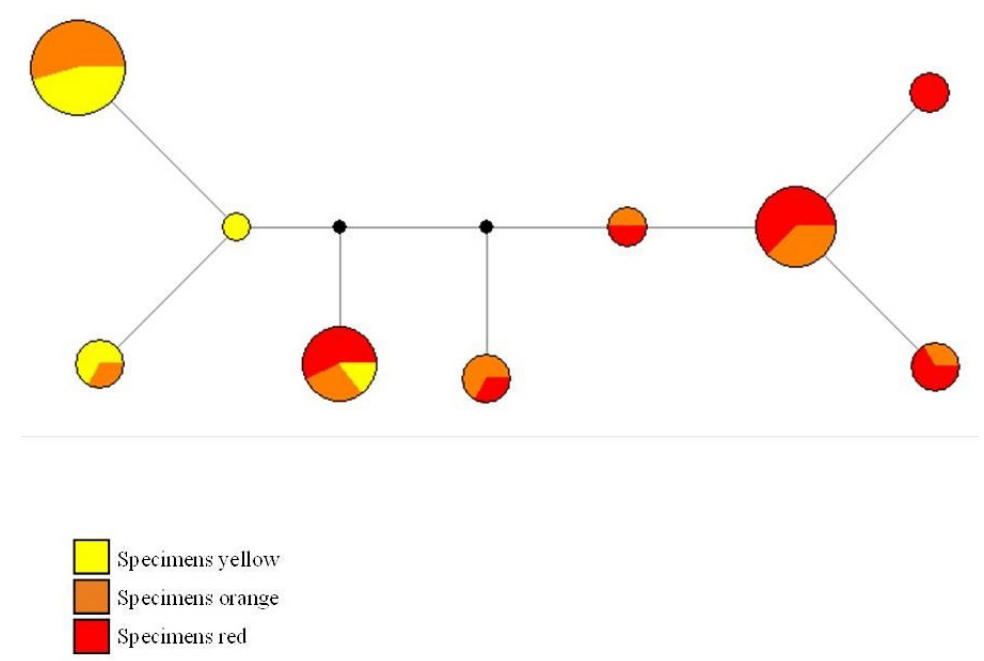

Figure 3. Network of connections between the haplotypes of Pachycoris torridus obtained from the analysis of minimum evolution using the Network program. Diameters of the circles are proportional to the frequency of each haplotype. The black spots represent a haplotype not sampled or extinct. Color denotes the actual color of each specimen analyzed (yellow specimens, orange specimens, red specimens).

\section{DISCUSSION}

The index of haplotype diversity obtained was elevated $(\mathrm{Hd}=0.872)$, demonstrating the high genetic diversity present in $P$. torridus. In a study of 40 specimens of Triatoma dimidiata using the mitochondrial gene ND4, Grisales et al. (2010) also observed high values of diversity $(\mathrm{Hd}=$ 0.863), revealing large variations among the Heteroptera studied.

We observed separation of the yellow and red phenotypes, and the orange phenotype appeared widely distributed in relation to the other two phenotypes studied. Almeida et al. (2002) analyzed four chromatic patterns of Triatoma rubrovaria and verified the existence of distinct genetic patterns related to different phenotypes. However, in our analysis there was no relationship between genetic and phenotypic patterns, demonstrating that due to the high genetic variability of $P$. torridus, several genetic patterns result in the same phenotype.

$P$. torridus is highly polymorphic, a characteristic that makes it difficult to identify and that has already resulted in a number of taxonomic mistakes. According to Monte (1937), color variations of $P$. torridus are not hereditary and the factors that may contribute to the differentiation of color are diverse and complex, such as temperature, digestion, existence of oxidases, sensitivity of the cells, humidity, age, and sex.

Gabriel and Franco (2012) studied the morphological aspects of $P$. torridus and observed that the color of spots on descendants may or may not differ from the color of spots on the female from which they were born, and descendants with different colors can result from the same 
oviposition. All adults that emerged showed a yellow color and, over the course of time, became orange, red, or remained the source color (Gabriel and Franco, 2012). They also noted that under laboratory conditions, red colored adults were longer-lived in relation to orange and yellow adults, and that age and sex did not influence the color of the spots. Consequently, hypotheses raised by Monte (1937) that the age and sex could contribute to color variability in $P$. torridus were eliminated.

Hollocher et al. (2000) demonstrated that the divergent melanization between the light and dark color of the abdomen of Drosophila involves a complex genetic architecture, including factors related to the $\mathrm{X}$ chromosome and to the autosomes, as well as paternal and maternal effects, revealing that there are genetic factors involved in the chromatic variations of insects. However, the genetic factors involved in the polychromatism of $P$. torridus have not yet been identified. Therefore, we conclude that the variations in color observed in $P$. torridus are singles and due to the high genetic variability of $P$. torridus, with several genetic patterns resulting in the same phenotype.

\section{Conflicts of interest}

The authors declare no conflict of interest.

\section{ACKNOWLEDGMENTS}

We are grateful to the agencies FAPESP (processes \#2008/09166-0, \#2010/16080-5 and \#2011/11064-9), CNPq, FAPERP (process \#37/2015), and FUNDUNESP for providing financial support.

\section{REFERENCES}

Almeida CE, Pacheco RS, Noireau F and Costa J (2002). Triatoma rubrovaria (Blanchard, 1843) (Hemiptera: Reduviidae) I: isoenzymatic and chromatic patterns of five populations from the State of Rio Grande do Sul, Brazil. Mem. Inst. Oswaldo Cruz 97: 829-834.

Bandelt HJ, Forster P and Röhl A (1999). Median-joining networks for inferring intraspecific phylogenies. Mol. Biol. Evol. $16: 37-48$. Bargues MD and Mas-Coma S (1997). Phylogenetic analysis of lymnaeid snails based on 18S rDNA Sequences. Mol. Biol. Evol. 14: 569-577.

Dotson EM and Beard CB (2001). Sequence and organization of the mitochondrial genome of the Chagas disease vector, Triatoma dimitiata. Insect. Mol. Biol. 10: 205-215.

Folmer O, Black M, Hoeh W, Lutz R, et al. (1994). DNA primers for amplification of mitochondrial cytochrome c oxidase subunit I from diverse metazoan invertebrates. Mol. Mar. Biol. Biotechnol. 3: 294-299.

Froeschner RC (1988). Family Scutelleridae Leach, 1815. In: Catalog of the Heteroptera or true bugs, of Canada and the Continental United States (Henry TJ and Froeschner RC, eds). EJ Brill, New York, 684-693.

Gabriel D and Franco DAS (2012). Aspectos Biológicos e Morfológicos de Pachycoris Torridus Scopoli, 1772 (Hemiptera: Scutelleridae) criados com pinhão-manso Jatropha curcas L., 1753, em laboratório. Científica 40: 156-163.

Grisales N, Triana O, Angulo V, Jaramillo N, et al. (2010). Diferenciación genética de tres poblaciones colombianas de Triatoma dimidiata (Latreille, 1811) mediante análisis molecular del gen mitocondrial ND4. Biomédica 30: 207-214.

Hall TA (1999). BioEdit: a user-friendly biological sequence alignment editor and analysis program for Windows $95 / 98 / N T$. Nucleic Acids Symp. Ser. 41: 95-98.

Hollocher H, Hatcher JL and Dyreson EG (2000). Genetic and developmental analysis of abdominal pigmentation differences across species in the Drosophila dunni subgroup. Evolution 54: 2057-2071.

Hoy MA (2003). Insect molecular genetics: an introduction to principles and applications. $2^{\text {nd }}$ edn. Academic Press, USA, 544.

Kimura M (1980). A simple method for estimating evolutionary rates of base substitutions through comparative studies of nucleotide sequences. J. Mol. Evol. 16: 111-120.

Librato P and Rozas J (2009). DnaSP v5: a software for comprehensive analysis of DNA polymorphism data. Bioinformatics 25: $1451-1452$.

Lima ADC (1940). Insetos do Brasil: hemípteros. Escola Nacional de Agronomia, Rio de Janeiro, 351.

Lyman DF, Monteiro FA, Escalante AA, Cordon-Rosales C, et al. (1999). Mitochondrial DNA sequence variation among 
triatomine vectors of Chagas disease. Am J. Trop. Med. Hyg. 60: 377-386.

Maes JM (1994). Catalogo de los Pentatomoidea (Heteroptera) da Nicaragua. Rev. Nicar. Entomol. 28: 1-29.

Marques OM, Rosário AG, França ES and Carvalho PCL (2012). Ocorrência de Pachycoris torridus (Scopoli) (Hemiptera: Scutelleridae) no estado da Bahia, Brasil. Magistra 24: 207-209.

Monte O (1937). Algumas variações nos desenhos e cores de Pachycoris torridus (Scopoli). Campo 8: 71.

Muraji M and Tachikawa S (2000). Phylogenetic analysis of water striders (Hemiptera: Gerroidea) based on partial sequences of mitochondrial and nuclear ribosomal RNA genes. Entomol. Sci. 3: 615-626.

Peredo LC (2002). Description, Biology, and Maternal Care of Pachycoris klugii (Heteroptera: Scutelleridae). Fla. Entomol. 85: 464-473.

Sanchez-Soto S, Milano P and Nakano O (2004). Nova planta hospedeira e novos padrões cromáticos de Pachycoris torridus (Scopoli) (Hemiptera: Scutelleridae) no Brasil. Neotrop. Entomol. 33: 109-111.

Silva AGA, Gonçalves CR, Galvão DM, Gonçalves AJL, et al. (1968). Quarto catalogo dos insetos que vivem nas plantas do Brasil. Seus parasitos e predadores. Parte 2 Tomo $1^{\circ}$, insetos, hospedeiros e inimigos naturais. Ministério da Agricultura, Rio de Janeiro, 622.

Sugumaran M (1998). Unified mechanism for sclerotization of insect cuticle. Adv. Insect Physiol. 27: 229-334.

Sugumaran M (2002). Comparative biochemistry of eumelanogenesis and the protective roles of phenoloxidase and melanin in insects. Pigment Cell Res. 15: 2-9.

Sugumaran M (2009). Complexities of cuticular pigmentation in insects. Pigment Cell Melanoma Res. 22: 523-525.

Tamura K, Stecher G, Peterson D, Filipski A, et al. (2013). MEGA6: Molecular Evolutionary Genetics Analysis version 6.0. Mol. Biol. Evol. 30: 2725-2729.

Wittkopp PJ and Beldade P (2009). Development and evolution of insect pigmentation: genetic mechanism and the potential consequences of pleiotropy. Sem. Cell Dev. Biol. 20: 65-71. 